\title{
Memórias de nosso convívio com o Professor Marcelo'
}

\author{
Memories of our daily lives with Professor Marcelo
}

Leonardo Vasconcelos Cavalier Darbilly ${ }^{2}$

Diana Costa de Castro ${ }^{3}$

\section{Um Sentimento de Saudade}

Abraçar a profissão de professor e de pesquisador não é, sabemos, a melhor opção para aqueles que consideram apenas os fins instrumentais do seu trabalho. Pertencer à "vida acadêmica" é mais do que escolher uma profissão; constitui-se em adotar um modo de vida diferente, e aquele que nele adentra passa a olhar para o mundo, na maior parte das vezes, com o olhar de estranheza do cientista, do estudante eterno. Seu gesto e forma de atuar passam naturalmente a ser aqueles do educador. No entanto, sabemos que, geralmente, algumas pessoas que optam por tal profissão não realizam efetivamente essa escolha com plena consciência das consequências que tal ofício acarreta, formando um enorme contingente de estudantes, futuros professores e pesquisadores que saem de suas cadeiras sem que possam refletir criticamente sobre o mundo do qual fazem parte e sobre sua própria área de atuação. Não obstante, nesse mesmo universo, alguns outros professores certamente se destacam por abraçar a vida acadêmica por inteiro, tornando-se, de fato, professores no sentido mais pleno da palavra, como era o caso do Professor Marcelo Milano Falcão Vieira.

É com o objetivo de prestar uma homenagem ao nosso querido Professor Marcelo, conforme o propósito desta edição especial do Cadernos EBAPE.BR, mas, também, com o intuito de registrar algumas das diversas experiências pelas quais passamos e aprendizagens do nosso convívio com ele, que nos motivamos a escrever as páginas que virão a seguir. Além disso, acreditamos que, ao fazê-lo, estamos deixando um registro para os que não tiveram o privilégio de estar tão próximos a ele, ainda que com as limitações inerentes a alguns relatos de poucas linhas, de alguns momentos que marcaram nosso convívio com o Professor Marcelo, bem como alguns dos ensinamentos que dele recebemos.

No mais, queremos dizer que para nós é um prazer reviver esses momentos guardados em nossa memória, e que o sentimento da saudade, por mais que pese e doa muitas vezes, também é bom e conforta quando aquele amigo que se foi nos deixa um legado tão rico e um exemplo de vida tão admirável. Como os leitores

\footnotetext{
Texto submetido em 09 de fevereiro de 2012 e aceito para publicação em 09 de março de 2012.

1 Nota de agradecimento - Endereçamos nosso carinhoso agradecimento à Janaína Machado Simões, também ex-orientanda do Professor Marcelo. É dela a ideia da estrutura destas páginas, e temos certeza de que também será por meio dela que alguns dos bons ensinamentos do nosso professor viverão.

2 Doutorando em administração pela Fundação Getulio Vargas/EBAPE; Professor da Universidade Federal Rural do Rio de Janeiro/IM; Pesquisador sob orientação do Prof. Marcelo Milano F. Vieira até seu falecimento e integrante do grupo de pesquisa Observatório da Realidade Organizacional, núcleo Rio de Janeiro. Endereço: FGV/EBAPE - Escola Brasileira de Administração Pública e de Empresas, Praia de Botafogo, 190 - $4^{\circ}$ e 5andares, Botafogo, CEP 22253-900, Rio de Janeiro - RJ, Brasil. E-mail: leonardo.darbilly@fgv.br

${ }^{3}$ Doutoranda em administração pela Fundação Getulio Vargas/EBAPE; Professora do Instituto Federal de Educação, Ciência e Tecnologia do Rio de Janeiro/Pinheiral; Pesquisadora sob orientação do Prof. Marcelo Milano F. Vieira até seu falecimento e integrante do grupo de pesquisa Observatório da Realidade Organizacional, núcleo Rio de Janeiro. Endereço: FGV/EBAPE - Escola Brasileira de Administração Pública e de Empresas, Praia de Botafogo, 190 - $4^{\circ}$ e $5^{\circ}$ andares, Botafogo, CEP 22253-900, Rio de Janeiro - RJ, Brasil. E-mail: diana.castro@fgv.br
} 
poderão notar, optamos por dividir o corpo da homenagem em duas partes, cada uma delas escrita por um orientando do Professor Marcelo, tendo ambos trabalhado com ele como seus assistentes de pesquisa durante o período de alguns anos. Tais relatos contêm percepções e exemplos vividos ao longo do nosso caminhar acadêmico com o apoio do Professor Marcelo. Esperamos que sirva de parâmetro para outros estudantes e como homenagem a essa figura que tanto admiramos.

\section{Memórias de uma Orientanda}

O Professor Marcelo costumava começar a primeira aula do período rememorando a história do surgimento da Administração como uma ciência que busca responder a pergunta: "como fazer as organizações funcionarem da melhor forma possível para ter mais aderência ao sonho da modernidade?" E lembrava que esse sonho, originalmente, estava ligado ao fato de que a produção em massa poderia gerar mais produtos e também dividi-los na sociedade proporcionando mais igualdade. Apesar dessa introdução algo romântica, as discussões, textos e pesquisas que se seguiam eram críticas a como a disciplina têm falhado nessa intenção. Deve ter vindo em parte daí sua vontade de se dedicar aos Estudos Organizacionais. Era tão orgulhoso de sua área de pesquisa que falava frequentemente para mim, com formação fora da Administração: "esqueça isso tudo, é bobagem, agora tu és pesquisadora de Estudos Organizacionais".

Outro momento de sua aula de que gosto de lembrar, e que deixava os alunos perplexos e apaixonados - no sentido vernacular e positivo da palavra -, era quando explicava a relevância como uma possibilidade de medir o desempenho das organizações, fazendo uma ligação com a noção de racionalidade substantiva e buscando em cada um dos alunos sentimentos de preocupação com as decisões que são tomadas na administração pública e que implicam diretamente a vida de todos nós. Para ele, relevância é muito difícil de perceber, de medir, mas a despeito disso, deveria ser buscada, sobretudo na administração pública, porque era a única medida de desempenho que estava ligada à questão ética. Questão essa que tem sido embaçada nos estudos de administração ultimamente, mas que precisava ser retomada. Para ele, havia um objetivo em fazer pesquisa em Administração e estudar Estudos Organizacionais: contribuir para um mundo melhor. E esse, ele nos ensinava, tinha de ser o nosso objetivo também.

Como orientador, a preocupação ética desde a escolha dos nossos temas de pesquisa era latente. Em uma das primeiras reuniões que tive com ele, lembro de me falar, com aquele jeito elegantíssimo e aprazível, ao mesmo tempo sério e engajado, com ar de dizer coisas relevantes, que ele tinha começado a estudar alguns assuntos porque o interessavam, porque ele olhava o mundo e percebia que havia algo errado, ou algo a ser melhorado, e queria fazer algo para tal. Assim, ele exemplificou-me tal posição com o estudo que havia realizado sobre o campo da pesca, dizendo-me que era um tema que eu poderia entender bem, já que ambos (como mais outras orientandas) viemos de uma cidade que teve seu apogeu econômico baseado na indústria pesqueira e que agora estava com graves problemas. Mas não era apenas isso; quando estudava as organizações, pensava, sobretudo, nas pessoas. Tendo realizado algumas consultorias no início de sua carreira, eventualmente usava-as como exemplo em aula, aproveitando o que tinha aprendido e visto em tais ocasiões, para fazer denúncias de como a aplicação de teorias organizacionais, como a das Relações Humanas, pode modificar de forma irremediável a vida das pessoas que trabalham nas organizações. Foi dessa forma que o Professor Marcelo me perguntou, demonstrando o interesse de um verdadeiro educador, a respeito do que me incomodava no mundo e, caso tal preocupação fosse também objeto de interesse do grupo, eu poderia pesquisar junto a ele. Caso não fosse, ele me apresentaria a outros professores que porventura se interessassem pelo assunto naquele momento. Meu interesse era o do grupo, felizmente.

Era de uma generosidade impressionante como orientador. Reservava um tempo, normalmente semanal, para conversar com todos os orientandos individualmente. As conversas eram habitualmente animadas e geravam novas ideias. Costumava acompanhar tudo o que os orientandos escreviam e também as nossas leituras e pensamentos a respeito das nossas pesquisas de graduação, mestrado e doutorado. Mas também falava sobre outros assuntos, amenidades e assuntos de interesse pessoal. Além disso, havia as pesquisas e as leituras em 
grupo, das quais participava bastante incentivando a todos. Esses encontros sempre se constituíam em bons momentos, regados, nos últimos tempos, a boas xícaras de chá. Tínhamos muitas xícaras na sala! Como meu orientador, o momento mais marcante foi quando ele me chamou para conversar sobre meu projeto de tese. Ele tinha o costume de sentenciar a cada um de nós conforme sua vontade: hoje vamos conversar sobre "tal coisa", e numa dessas sentenças ouvi "sua tese"! Sentei-me à sua frente, com muita vergonha de mencionar aquelas ideias malucas, pouco fundamentadas e mal organizadas ainda na minha cabeça. Tinha levado, a seu pedido, uma página rascunhada, com poucas linhas, contando de onde havia tirado a ideia, como tinha visto o mundo e o que me incomodava nele, e o que eu propunha então diante disso. Enquanto falava, ele me olhava com pouca expressão no rosto. Depois riu e disse: "fala de novo!" Repeti tudo aquilo. Ele, então, pensou seriamente, demonstrou simpatia pela ideia e lembrou-me de que não tinha, ele próprio, leituras sobre o assunto, mas que parecia interessante, e perguntou se eu estava ciente de que o trabalho seria bastante extenso e a leitura um tanto quanto pesada. Eu respondi que sim. Ele então falou: "está bem, vamos fazer isso juntos, vou ler os livros contigo!" Na penúltima semana em que esteve na Fundação Getulio Vargas, chegou trazendo um livro e disse: "Olha, comprei para tua tese. Sei que não é bem o enfoque que queremos dar, mas é um começo, vamos lê-lo". O trabalho era extenso, e um pesquisador reconhecido como ele não precisaria, àquela altura, realizar leituras pesadas em outras áreas correlatas, como teríamos de fazer. Mas acreditar na ideia e, muito mais do que isso, caminhar junto, foi, para mim, o maior exemplo de generosidade e de grandiosidade do Professor que ele era.

Como professor, preocupou-se, ainda, em me ensinar (e a outros de seus orientandos) a dar aulas. Assim, levou-me para a sala de aula como sua monitora. Certo dia me ligou, de véspera (isso era comum, e já tinham me avisado), informando que a aula da manhã seguinte seria conduzida por mim. Era um assunto péssimo, do qual eu não entendia nem gostava. Foi a pior aula da minha vida, mas ele a assistiu pacientemente e, depois disso, comentou que não havia sido tão ruim, conversou comigo e sugeriu melhorias para as próximas aulas que eu viesse a dar. Fez isso algumas vezes mais. Eu sempre ficava nervosa quando estava à frente dele! Já ministrava aula em outra universidade, mas, com ele, a quem tanto admirava, era diferente. Entretanto, sempre soube que essa oportunidade era ótima e rara, portanto busquei aproveitar seus ensinamentos ao máximo: sempre ministrar a aula de pé, ter cuidado com o tom de voz, explicar o motivo das atividades de classe e das extraclasse, oferecer ajuda aos alunos para a condução dos trabalhos que eles teriam de desenvolver, buscar sempre exemplos atuais e próximos à realidade dos alunos, entre outros tantos. Acredito que talvez seja por essa razão que algumas pessoas afirmem que os orientandos do Professor Marcelo são parecidos em sua forma de dar aula. Sua influência em todas as esferas da nossa "vida acadêmica" era muito forte e ele acompanhava cada passo nosso como um pai acompanha os passos do filho. Primeiramente, mais de perto, e após algum tempo se afastando aos poucos para que pudéssemos caminhar sozinhos.

Nós tínhamos conhecimento, desde o início, da doença dele. Foi ele mesmo quem contou quando descobriu. Mas resolvemos todos manter grande discrição sobre o assunto, apoiando a sua postura. Mas talvez por ele ter conseguido equalizar tão bem esses momentos difíceis com momentos tão agradáveis e produtivos, em uma imagem quase sempre muito forte é tão difícil hoje ainda acreditar que tudo aconteceu tão rápido. Entrar na "nossa sala", no quinto andar, e pensar que ele não vai entrar, tão elegante e perfumado saudando um bom dia, ou fazendo alguma reclamação "rabugenta" e engraçada, é tão difícil quanto impossível explicar.

O professor Marcelo foi um acadêmico completo, um excelente educador, um excelente pesquisador, atento às mudanças da realidade prática, em constante atualização, um excelente coordenador, organizadíssimo, e um amigo. Foi generoso, engajado, ético e paciente, e é e será, por tudo isso, um grande exemplo. E é por isso que eu prefiro sempre pensar em tudo que ele deixou e que se faz ainda muito presente do que no que se foi. Pessoas que, como ele, deixam tanto legado não morrem; pelo menos não como as outras, porque muito delas vive em todas as outras pessoas que em seus exemplos se espelham. 


\section{Memórias de um Orientando}

Meu primeiro contato com o Prof. Marcelo ocorreu em junho de 2002, no $13^{\circ}$ andar do prédio da Fundação Getulio Vargas, quando ainda cursava a metade do curso de graduação em Administração de Empresas de outra instituição particular localizada no Rio de Janeiro e quando me encontrava em busca de um estágio que me pudesse prover alguma experiência inicial no campo. À época, havia passado por um processo seletivo realizado pelo departamento de $\mathrm{RH}$ da FGV sem que, no entanto, soubesse exatamente para qual área seria direcionado caso fosse aprovado. Após alguns dias, recebi um telefonema no qual fui informado que deveria procurar um professor daquela instituição que estava à procura de alguém para trabalhar com ele como assistente de pesquisa. À época, nunca havia trabalhado como bolsista de iniciação científica e, mais ainda, não tinha ideia a respeito do que isso significava - o que me fez sentir certa insegurança pouco antes de entrar em sua sala, no referido andar daquela instituição. Lembro-me bem de que, imediatamente após fazêlo, o Professor Marcelo, com sua habitual simpatia e com um sorriso estampado no rosto, tratou de me deixar mais à vontade em sua presença, conversou comigo sobre suas origens e sobre a cidade de onde veio, no Rio Grande do Sul, fez algumas perguntas com o intuito de obter algumas informações sobre meus interesses, me conhecer melhor e também explicar a respeito de algumas das atribuições necessárias para se trabalhar com pesquisa de cunho acadêmico.

Poucos dias depois, fui por ele chamado em definitivo e, a partir de então, iniciou-se uma relação que não ficaria meramente restrita aos papéis de chefe e estagiário - não obstante o vínculo formal no qual me encontrava na instituição -, mas se configuraria, ao longo do tempo, como uma relação entre um verdadeiro orientador e formador e um estudante de Administração e aprendiz de pesquisador.

Uma de minhas principais recordações nesses primeiros dias de trabalho com o Professor Marcelo marcante, em minha visão, por caracterizar exatamente sua forma de lidar não apenas com aquelas pessoas que, com o passar do tempo, foram se somando à sua equipe de trabalho na EBAPE, mas também com todas as demais que a ele se dirigiam - foi quando ele me solicitou que lesse o projeto de pesquisa no qual estava trabalhando, "Análise institucional da dinâmica de setores industriais: uma análise da indústria pesqueira nos Estados do Rio de Janeiro e do Rio Grande do Sul". A principal atribuição que me foi por ele solicitada, nesse momento, era a de ajudá-lo no desenvolvimento de tal pesquisa.

O objetivo do projeto pareceu-me extremamente interessante e, igualmente, a preocupação de se estudar um setor sobre o qual possuía pouca ou nenhuma noção. No entanto, a perspectiva teórica na qual ele estava baseado, a abordagem neo-institucional proveniente da Sociologia - à época, predominante no Observatório da Realidade Organizacional, grupo de pesquisa com núcleos no Rio de Janeiro (do qual ele era coordenador), Recife, Santa Catarina e Rio Grande do Sul - era bastante nova para mim. Comentei, então, que havia alguns pontos relacionados à teoria que não havia compreendido bem. Ele respondeu que reservaria quantos dias fossem necessários para me auxiliar a compreender a abordagem da forma mais aprofundada possível e dirimir qualquer dúvida minha relativa ao projeto. Complementou, ainda, pedindo que não me acanhasse em elaborar as perguntas que me fossem necessárias. Posso dizer, então, que a partir desse momento passei a obter uma formação teórica sólida na área das organizações, possível graças à preocupação verdadeira por parte do Professor Marcelo de levar seus orientandos a crescer em conhecimento e melhorar a cada dia.

Devo mencionar, também, que, desde o início do trabalho com o Professor Marcelo, aprendi não apenas a trabalhar com pesquisa, mas, sobretudo, recebi de sua parte um grande incentivo para que realizasse o exame seletivo para o curso de mestrado acadêmico na EBAPE/FGV, ainda que inicialmente tivesse dúvidas concernentes à escolha entre a academia e o mercado. Entretanto, já estava tomado pela satisfação de ter participado da realização de um projeto de pesquisa longo e que me trouxe grande conhecimento na área de estudos organizacionais, e também de ter tido a oportunidade de publicar meu primeiro artigo em conjunto com um professor de alto reconhecimento acadêmico, caso do Professor Marcelo. Com seu constante apoio, iniciei minha trajetória na carreira acadêmica já refletindo sobre a possibilidade de tentar seguir os passos 
daquele que seria meu orientador não apenas no mestrado, mas, também, no curso de doutorado alguns anos depois.

Tendo cursado inúmeras disciplinas lecionadas por ele nos cursos de mestrado e doutorado - tais como Pensamento Organizacional, Análise de Organizações Culturais, Pesquisa Qualitativa em Administração, Gestão Estratégica de Pessoas e Análise de Dados Qualitativos -, sinto-me à vontade para afirmar que sua postura em sala de aula e o modo como conduzia as discussões as quais eram travadas - baseadas nos excelentes textos de leitura que costumava indicar a seus alunos - me chamavam atenção por demonstrar claramente seu interesse em ouvir atenciosamente as dúvidas de seus alunos, esclarecê-las e debater os pontos centrais relacionados à abordagem ou ao tópico sobre o qual se refletia. Aliás, entre algumas das características mais marcantes do Professor Marcelo, em minha visão, estavam exatamente o brilhantismo relacionado às suas argumentações, sempre fundamentadas epistemológica e teoricamente, a facilidade que possuía em realizar abstrações conceituais e de estabelecer relações entre diferentes abordagens e, mais ainda, a visão crítica que sempre manteve em relação à Administração e à usual adoção de teorias estrangeiras para análise dos fenômenos que ocorrem nas organizações localizadas em nosso contexto.

Aliás, com relação a este último ponto, deve-se observar que os orientandos do Professor Marcelo eram constantemente estimulados, seja individualmente ou de forma coletiva, a ler os autores nacionais ligados ao pensamento administrativo que tanto contribuíram para que pudéssemos refletir a respeito da construção de uma teoria organizacional brasileira, tais como Guerreiro Ramos, Fernando Prestes Motta e Maurício Tragtenberg, além de autores relacionados a outras áreas de conhecimento, mas que também são essenciais para que possamos compreender o contexto brasileiro, tais como Celso Furtado e Milton Santos. O pensamento deste último autor vinha sendo objeto de especial interesse por parte do Professor Marcelo em seus últimos anos de vida, especialmente devido à possibilidade que ele via na utilização dos conceitos de espaço e território como forma de se entender melhor a dinâmica das organizações.

Ainda no tocante ao papel que exercia como orientador, vale ressaltar outra característica intrínseca ao Professor Marcelo; a atenção que destinava à leitura dos trabalhos de seus orientandos, a qual era feita sempre da forma mais cuidadosa e interessada possível. Nesse sentido, não posso deixar de me recordar das vezes em que, estando em sua sala, chamou-me alertando que gostaria de conversar comigo a respeito de minha dissertação ou do início de meu projeto de tese. Pedia-me para sentar na cadeira localizada em frente à sua mesa e, então, mostrava-me o trabalho contendo diversas páginas com as orelhas dobradas e algum tipo de observação feita por ele à caneta. Antes que eu as lesse, entretanto, fazia questão de passar página por página e explicar-me todas as anotações que fizera para que não restassem dúvidas sobre o que era para ser feito e, também, para que não se esquecesse de me perguntar questões que ele considerava importantes. Tais observações iam desde questões relativas à forma de frase e ortografia (deve-se frisar, a esse respeito, a impecabilidade da escrita inerente aos textos do Professor Marcelo) a questões pertinentes ao conteúdo, argumentação e ligação entre as ideias contidas no texto.

Ainda, com relação à figura de chefe e coordenador de grupo, também devo dizer que as recordações que carrego comigo do Professor Marcelo serão sempre as melhores possíveis. Arrisco-me a afirmar que, talvez, dentre todas as qualidades mencionadas anteriormente, aquela que mais diz respeito à sua essência e ao seu modo de ser é a amabilidade, refletida no tratamento digno dispensado aos que trabalharam em sua equipe e com ele compartilharam sua sala no quinto andar do prédio da EBAPE/FGV. Assim, via claramente que o Professor Marcelo se preocupava deveras com seus orientandos, se estavam bem ou não em suas vidas pessoais, se estavam gostando das disciplinas que cursavam (em especial as dele) em um determinado semestre. Além disso, graças à "confiança" que nutria por sua equipe - segundo ele mesmo -, permitia-se desabafar constantemente sobre questões que muitas vezes o preocupavam. O modo sempre respeitoso como tratava as pessoas que com ele trabalhavam permanecia mesmo naqueles dias em que porventura não estivesse de bom humor, o que para alguns de nós já transparecia desde o momento em que ele abria a porta de sua sala e nos cumprimentava. Tal "percepção" levava-o a gargalhadas quando comentávamos sobre tal assunto em outra ocasião. 
A perda do Professor Marcelo - para mim e certamente para seus outros orientandos e ex-orientandos significa uma ruptura de uma etapa de vida e o início de outra, em que não mais poderei contar com a figura do orientador, professor e formador presente quase todos os dias e que me enriquecia o conhecimento relativo à esfera das organizações de forma constante. Entretanto, seu profundo saber e, mais ainda, o espírito crítico que marcou seu pensamento certamente não apenas permanecerão nos inúmeros artigos e livros que escreveu durante sua carreira acadêmica, mas também se refletirão nos trabalhos e na vida daqueles que com ele puderam conviver.

\section{Gratidão e Compromisso}

Como seus orientandos e membros de sua equipe de pesquisa no âmbito da EBAPE/FGV e, também, como participantes do Observatório da Realidade Organizacional do Rio de Janeiro, gostaríamos de encerrar nossos relatos agradecendo a oportunidade e o privilégio que tivemos de trabalhar com o Professor Marcelo ao longo desses anos e os momentos de convívio que com ele tivemos que tanto nos ensinou, motivou e nos desenvolveu como pessoas e pesquisadores da área de organizações. Comprometemo-nos, também, a nos esforçarmos para prosseguir da melhor forma possível com o belo trabalho que ele realizava, sempre dotado da preocupação em desenvolver uma abordagem organizacional que pudesse ir ao encontro do contexto brasileiro. Não obstante o fato de tal tarefa não ser de fácil realização, dado o enorme conhecimento que o Professor Marcelo possuía acerca do mundo das organizações e o talento natural que carregava consigo, acreditamos que aquilo que por ele nos foi ensinado seguirá vivo e se refletirá nas produções acadêmicas que porventura viermos a realizar futuramente. 